\title{
Preclinical medical students' performance in and reflections on integrating procedural and communication skills in a simulated patient consultation
}

I Treadwell, DCur, HED

Skills Centre, Sefako Makgatho Health Sciences University (formerly Medunsa Campus of the University of Limpopo), Pretoria, South Africa

Corresponding author: I Treadwell (ina.treadwell@gmail.com)

Background. An effective patient-centred consultation requires the seamless integration of procedural (technical) and communication skills. Research has shown that the two sets of skills should not be taught or assessed separately; yet, clinical communication education has become separated from other parts of medical education.

Objectives. To assess students' performance of integrated procedural and clinical communication skills in a simulated consultation, and analyse and interpret their reflections on the value and challenges of these integrated assessments.

Methods. A mixed-method study was conducted to assess a convenience sample of 207 third-year medical students' integration of procedural and consultation skills in a simulated patient consultation and explore their self-assessment and reflections on the value of the assessment.

Results. The average percentages scored for procedural and communication checklist items were compared. Facilitators and participants scored procedural skills significantly higher, indicating poor integration of communication skills. A thematic analysis of written reflections revealed that students learned by: (i) experiencing an authentic consultation; (ii) integrating their procedural and communication skills as well as their knowledge and skills; (iii) experiencing the assessment as learning; and (iv) becoming aware of the effects of emotion.

Conclusion. Although the majority of students were not able to integrate their skills in performing a simulated consultation, they nonetheless appreciated the value of the assessment as a learning experience.

Afr J Health Professions Educ 2015;7(2):165-169. DOI:10.7196/AJHPE.334

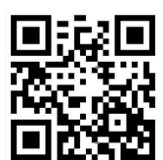

For various reasons training in clinical communication has become separated from other aspects of medical education and tends to be dealt with early in the curriculum. ${ }^{[1]}$ Performing a clinical procedure involves two sets of skills - those related to conducting the procedure and those related to communicating with the patient. Although inextricable in practice, these sets of skills are usually taught separately, often by different departments in an institution. ${ }^{[2]}$ Teachers of clinical communication, whether faculty or clinically based, may not share the learning goals for acquiring communication skills, which may lead to a disjointed learning experience for students. ${ }^{[1]}$

As clinicians are expected to integrate technical with communication and other professional skills, these should not be taught separately. Nontechnical skills, although essential in carrying out a clinical procedure on a conscious patient, can be ignored in simulation-based teaching. ${ }^{[2]}$ Other disadvantages of simulation include learning in isolation from the clinical context and assessment practices that traditionally focus only on the technical elements of clinical procedural skills. ${ }^{[3]}$ In an effort to avoid these possible disadvantages of simulation, realistic clinical scenarios can be created by linking bench-top models with simulated patients (SPs). Students can then perform procedures in a safe environment, where many of the contextual cues of clinical practice are recreated. ${ }^{[2]}$ SPs are usually lay people who are trained to portray a patient with a specific condition. When trained to play a role during an examination in a consistent way - one which does not vary from student to student - they are referred to as standardised patients.
Seamless integration of the procedural and communication skills is a process that requires practice and reflection. Reflection, defined as awareness or analysis of one's own learning or thinking processes, is regarded as an essential skill in learning and metacognition. ${ }^{[4]}$ Reflection on action stimulates the student to consciously re-evaluate the experience and decide what could be done differently the next time he/she is in the same situation. Structured reflection after a clinical encounter, either oral or written, is therefore a useful strategy to enhance learning and reasoning. ${ }^{[1]}$

At the University of Limpopo (Medunsa campus) in Ga-Rankuwa, $25 \mathrm{~km}$ north-west of Pretoria, South Africa, students are introduced at the beginning of their medical degree programme to procedural and clinical communication skills as separate skills. During the first 3 years, the focus is on history taking and communication skills; the focus widens to include consultation skills in their third year. Procedural skills include urine testing, venepuncture, intravenous infusions, basic clinical examination of adults, including vital signs and anthropometric measurements, palpation of a pregnant abdomen, normal delivery and repair of an episiotomy. Several disciplines, in collaboration with the Skills Centre, are responsible for the teaching and assessment of these skills. These preclinical students have limited experience of the clinical workplace and working with patients. The ultimate accomplishment would be the integration of their acquired skills in a patient-centred consultation in preparation for their years of clinical training and future role as doctors.

Assessing the students through a patient-centred consultation will provide an opportunity to explore their ability to integrate skills and 
allow lecturers to determine the influence of this assessment approach on their learning. The questions that arise are how well preclinical medical students integrate procedural and clinical communication skills, despite having acquired them separately during various academic blocks; and how these students learn by being assessed in a simulated consultation that requires integrated skills.

It is hoped that this research will provide sufficient evidence of the importance of using SPs in integrated Objective Structured Clinical Examinations (OSCEs) at Medunsa and will pave the way to the enhancement of the integration of procedural and communication skills throughout the medical curriculum.

\section{Objectives}

The aims of the study were: (i) to determine preclinical medical students' ability to integrate procedural and communication skills in a simulated consultation; and (ii) to determine which aspects of the simulated consultation they valued as a learning experience.

The objectives were:

- to assess students' performance of integrated procedural and clinical communication skills in a simulated consultation

- to analyse and interpret students' reflections on the value and challenges of the integrated assessments.

\section{Methods}

A mixed-method study was conducted: a descriptive study to observe and assess students' performance in the consultation OSCE and a qualitative inquiry to explore participants' reflections on their learning through the integration of procedural and clinical communication skills in a simulated consultation. A qualitative inquiry was appropriate in studying process evaluation, as participants' reflections are considered a key process. ${ }^{[5]}$

The population included all students enrolled in the third year of medical studies at Medunsa in 2012 and who were assessed during the mandatory end-of-year OSCE. All students $(N=250)$ signed an informed consent form, but the data of only 207 (83\%) were used owing to incomplete assessment records. Ethical clearance for conducting the study was obtained from the Medunsa Research and Ethics Committee.

This newly introduced OSCE was conducted during the only free time available in the students' timetable, and it allowed for only a 15-minute assessment per student. Four scenarios were developed by a panel, comprising the third-year students' practice co-ordinator and 4 facilitators from the Skills Centre. The panel ensured that the scenarios for the consultations were structured in such a way that they were balanced with regard to difficulty and time allowed to perform the required skills. Each scenario comprised skills the participants had acquired during the first 3 years of study. These included the essential history data, vital signs and instructions on the focused physical examination, and 2 skills to be performed on a young, female standardised patient (Box 1).

An assessment checklist was compiled for each consultation by combining previously used instruments for the individual skills, including items covering the communication skills required in the scenario. Each item on the checklist was rated 'competent', 'incompetent' or 'not done'. Content validity of the assessment checklists was assured by 4 facilitators involved in teaching procedural and clinical communication skills, who validated the appropriateness of the items on the checklists.

All activities took place in the Skills Centre. Prior to the OSCE, the participants were orientated regarding the expectations of a SP-centred consultation, and the individual assessment checklist was made available online to ensure that learners were aware of the task requirements and major components of a given task. The advantages of students having access to assessment tools before practical examinations are supported in the literature. ${ }^{[6,7]}$ Neal et al. ${ }^{[7]}$ demonstrated that trainees provided with a checklist beforehand performed significantly better in their medical management and non-technical performance during a simulated episode. Participants had the opportunity for revision and supervised practice of the individual skills mastered in their first year of study.
On completion of each OSCE session, the participants assessed their performance using a checklist, similar to the one used by the assessor. They also recorded their reflections in writing, guided by two questions: (i) Did the integration of communication and procedural skills on an SP help you to learn?; and (ii) What did you experience as valuable and challenging in the OSCE? Reflections were written individually and directly after assessments to ensure that students' views were not influenced by discussions with fellow participants.

The quantitative data collected in the study were captured on Excel spread sheets. Data capturing was verified and validity checks were performed as part of the data-cleaning process. The average percentages of competent performances in procedural and clinical communication skills items were compared using the Fisher exact test. All statistical tests were two-sided and $p$-values $\leq 0.001$ were considered significant.

A systematic process was used to identify themes from the written reflections. The researcher and the third-year co-ordinator read and reflected upon the data independently. They identified the themes and categories that emerged. Thus, they indexed and sorted the data using the constant comparative method. ${ }^{[8]}$ The themes and categories that emerged were identified through iterative (thematic) analysis. Consensus on the 4 main themes was reached through further perusal of the data. Quotations were used to illustrate some of the participants' views in their own words, adding to the validity and reliability of the results.

\section{Results \\ Participants' performance of procedural and clinical communication skills}

The average scores allocated by the facilitators were compared with the average self-assessment scores of the participants. The facilitators and

\section{Box 1. Example of an OSCE scenario and instructions}

Mrs ... is a 27 -year-old woman who is making her first visit to the antenatal clinic.

The clinic nurse has already:

- obtained her history: LMP (2012/01/01), EDB (2012/10/01), gravida 2 and para 1

- checked her temperature $\left(37^{\circ} \mathrm{C}\right)$, pulse $(80 \mathrm{bpm})$ and weight $(78 \mathrm{~kg})$

- given her health education about lifestyle issues (importance of good nutrition and avoidance of tobacco, alcohol and drugs)

Use this time to plan your consultation with Mrs ..., which must include the following procedures:

- abdominal palpation to determine the gestation and lie of the fetus

- blood pressure measurement

- urine test 
Table 1. Facilitator and participant scores for procedural and communication skills $(n=207)$

\begin{tabular}{|c|c|c|c|c|c|c|}
\hline \multirow[b]{2}{*}{ Assessor } & \multicolumn{2}{|c|}{ Procedural skills } & \multicolumn{2}{|c|}{ Communication skills } & \multirow{2}{*}{$\frac{\text { Difference }}{\%}$} & \multirow{2}{*}{$\frac{\text { Significance }}{p}$} \\
\hline & $\%$ & SD & $\%$ & SD & & \\
\hline Facilitators & 71.3 & 17.1 & 50.8 & 21.9 & 20.5 & $<0.0001$ \\
\hline Participants & 68.8 & 19.6 & 54.3 & 23.1 & 14.6 & $<0.0001$ \\
\hline
\end{tabular}

Table 2. Facilitator and participant scores for procedural skills of participants who repeated the OSCE $(n=53)$

\begin{tabular}{|c|c|c|c|c|c|c|}
\hline \multirow[b]{2}{*}{ Assessor } & \multicolumn{2}{|c|}{ OSCE 1} & \multicolumn{2}{|c|}{ OSCE 2} & \multirow{2}{*}{$\begin{array}{c}\text { Difference } \\
\%\end{array}$} & \multirow{2}{*}{$\begin{array}{c}\text { Significance } \\
p\end{array}$} \\
\hline & $\%$ & SD & $\%$ & SD & & \\
\hline Facilitators & 54.8 & 13.4 & 83.5 & 11.4 & 28.7 & $<0.0001$ \\
\hline Participants & 60.6 & 19.7 & 75.7 & 16.3 & 15.1 & $<0.0001$ \\
\hline
\end{tabular}

Table 3. Facilitator and participant scores for communication skills of participants who repeated the OSCE $(n=53)$

\begin{tabular}{|c|c|c|c|c|c|c|}
\hline \multirow[b]{2}{*}{ Assessor } & \multicolumn{2}{|c|}{ OSCE 1} & \multicolumn{2}{|c|}{ OSCE 2} & \multirow{2}{*}{$\begin{array}{c}\text { Difference } \\
\% \\
\end{array}$} & \multirow{2}{*}{$\begin{array}{c}\text { Significance } \\
p\end{array}$} \\
\hline & $\%$ & SD & $\%$ & SD & & \\
\hline Facilitators & 32.7 & 14.7 & 61.9 & 21.8 & 29.2 & $<0.0001$ \\
\hline Participants & 39.3 & 16.2 & 62.2 & 20.1 & 22.9 & $<0.0001$ \\
\hline
\end{tabular}

participants scored procedural skills significantly higher than communication skills (Table 1).

There was a highly significant improvement in both procedural skills (Table 2) and communication skills (Table 3 ) as scored by facilitators and participants in the second OSCE for the 53 participants who scored $<60 \%$ in the first OSCE. As in the first OSCE, the communication skills were scored significantly lower than the procedural skills by facilitators (21\% lower) and participants (13.5\% lower).

\section{Participants' written reflections on the value and challenges of the integrated assessment}

Almost all participants (94\%) reported that the integration of communication and procedural skills on an SP had helped them with their learning. Themes identified in the analysis of participants' reflections on what they regarded as valuable to their learning and challenging about the OSCE correlated with some recognised learning strategies (authentic learning, integrative learning, assessment as learning) and the impact of emotions on learning.

\section{Authentic learning (materials and activities} framed around 'real life' contexts)

- Two recurring values emerging from participants' responses were that the learning was realistic and relevant:
'Doing a consultation as required in practice is relevant and more realistic'

'A real consultation helps the learning process.' 'It felt real ... communicating while doing procedures.'

'The OSCE gave us a chance to know what to expect and deal with it in real settings.'

- The use of SPs humanised the consultation and was the most important element in making the consultation realistic:

'Having a "real" patient puts things into perspective.'

'Working with a real person makes the skill come alive.'

'I learnt that there is much more to a patient than just the condition.'

'I realised the importance of not just examining patients as if they were objects'

'One can see a facial expression if not comfortable when a procedure is done on him.'

- Various aspects of SP encounters challenged the participants:

'It was a challenge to explain the concepts to the patient'.

'Having to explain to the patient some words like vocal fremitus .... '

'I did not make the patient feel at ease. He must have been traumatised.'
'Encounters with a patient [SP] is intimidating but helps exploring yourself and learning from your own mistakes.'

'Communication was a challenge - I was thinking about what the assessor wanted to hear and not considering the patient.'

- The participants commented on the value of the experience in preparing them for future interactions with patients:

'It resembles more or less the situation you will be in in the future.'

'It gave me the opportunity to practise what I would do in real life.'

'Time was a challenge ... [OSCE] valuable for time management.'

- The scenario provided a realistic simulation which outlined the step-by-step process of a consultation. Participants appreciated the value of the structure in helping them to conduct the consultation:

'The preparation ... helped me to do the skill in a systematic manner.'

'Sometimes I had to wait and recall what is next, it is not in me yet.'

'Remembering sequence and doing procedure accurately was a challenge.

'Being a doctor and deciding what to do next made me enjoy the OSCE.'

'It is motivating for me to look back at the stuff I have learned in first year and second year. I also learned some new stuff. I now see that medicine is a life learning process.'

\section{Integrative learning}

- Integration of knowledge and procedures: [The OSCE] ' . .. allowed us to integrate knowledge and skills we have acquired in the last 3 years. It [the OSCE] ' ... integrates everything we have learnt but ... doing what I have read was a challenge.'

'The procedures seem easy when going through them theoretically.'

'When theory is put into practice ... you understand the procedure and become confident in performing it.'

'Correlating the information to the procedure helps to understand the reason for doing certain procedures.'

'Having to take the blood pressure and relate it with the history and talking to the patient helps thinking and integrating what I have learned.' 
- Integration of procedures and communication:

This was the first occasion where participants were required to integrate both aspects of a consultation, providing them with insight into the challenges posed.

'The OSCE made me aware of the importance of incorporation of skills and communication - I didn't realise it was this important.'

'Integration is a challenge ... speaking and doing skills.'

'Synchronising the whole procedure and getting good rapport with the patient'.

\section{Assessment as learning}

- Participants reported feeling under pressure when preparing for the assessment and becoming aware of what they lacked:

'The OSCE was a good idea but nerve wracking - it forced me to learn. Students only learn well when pressure is put on them.'

'OSCEs help me to practise and make learning a nice but challenging experience.'

'Skills need a lot of practice - even if you think you know them. Practice makes perfect.'

'Helps you to see your weak points and where you must improve'.

'Showed me that I wasn't prepared and I have to put in extra effort.'

'I found out where I'm still lacking.'

'It made me aware of the silly mistakes that can be done in the ward.'

'I realised that skills need to be constantly done in order to perfect the skill.'

\section{Impact of emotion on learning}

- Participants experienced stress and the desire to cope with the situation: 'The OSCE stresses you up ... it helps to get used to the situation.'

'Great learning experience to work under pressure ... learn to calm down.' 'It gives you a feel of what it will be like and calm the nerves before you are in a situation where there is no one to assist you.'

'Anxiety ... I need to find a way to deal with it ... try to stay composed.'

- Some participants viewed their anxiety/stress/nervousness as the reason for their failure to perform better:

'I was so nervous I fumbled the whole thing.'

'Nervous ... forget to mention vital stuff.'

'Being scared makes it harder.'

'I was shaking and nearly pricked myself.'

- Others experienced positive emotions:

'Gain confidence in interacting with your patients.'

'It made me feel confident enough to face patients at hospital.'

'It made it more real, somewhat more enjoyable.'

'Being the doctor and deciding what to do next made me enjoy the OSCE.' 'I loved the adrenaline that working against time gives you.'

'Communication is always fun but the challenge was trying not to mess up with skills.'

\section{Discussion}

The students, who were taught communication skills by different departments and separately from procedural skills in the Skills Centre, performed significantly worse in communication skills than in procedural skills when both were required in a consultation. Such an obvious divide in performance on two sets of skills could be the effect of a neglect of interpersonal skills in simulation-based teaching of procedural skills. ${ }^{[2]}$ This is aggravated by assessment practices that focus only on the technical elements of clinical procedural skills, ${ }^{[3]}$ which is currently the case at Medunsa.

Almost all the students in the study experienced the OSCE as a valuable learning experience. This also became apparent in the second OSCE, where the scores of the students who were repeating the OSCE increased significantly in both the procedural and communication items. Similar to findings by Kneebone et al., ${ }^{[2]}$ students seemed to have learned through reflecting on their performances, and by using rating scales and checklists identical to those of the facilitators. The improved performance may also have been influenced by students' awareness of their shortcomings, gained through reflection on their experience.

Students perceived the value of the OSCE as being its similarity to an encounter with a real patient. Learning is best achieved in an authentic learning environment in circumstances that resemble the real-life application of knowledge. ${ }^{[9]}$ Nestel et al. ${ }^{[10]}$ emphasise that scenarios should provide realistic simulations and prove feasible in terms of time, facilities and resources. Scenario-based assessments should reflect real-world issues of patient-centred care.

The authentic experience in this study was created primarily through the use of SPs, who humanised the consultation and posed the challenges of dealing with human beings. Walker et al. ${ }^{[11]}$ observed that SPs provide students with an experience that is consistent with reality, increasing the validity and depth of the learning experience.

Authenticity with regard to preparation for future patient encounters was also valued. Providing a concrete learning experience had a positive impact on students' learning processes. Experiential learning, or learning by doing, emphasises the role of experience as central to the learning process. It engages students and challenges their ideas and beliefs, encouraging them to create new knowledge. ${ }^{[12]}$ Learners must link their current experiences with those in the past and in the future. ${ }^{[13]}$

The many varieties of integrative learning include integrating skills and knowledge from multiple sources and experiences and applying theory to practice in various settings. ${ }^{[14]}$ Students realised the value of integrating knowledge and skills that they had learnt in their first year with that which they were learning in the current year. Building on information promotes learning and follows the constructivist theory that learning takes place in context. The consultation evoked a deep approach to learning through students seeking to understand the process through integration. Promoting student reflection on their learning processes may enable the successful transfer of these integrated skills to other procedures. ${ }^{[2]}$ Nestel et al. ${ }^{[10]}$ recommend that all tasks in a scenario should be contextualised, requiring students to combine technical, communication and other professional skills. Supporting the findings of Kneebone et al. ${ }^{[2]}$ students found the opportunity to integrate valuable communication and procedural skills and believed it was an appropriate learning experience. Consumers of healthcare services are increasingly demanding more considerate communication in healthcare. This may be achieved, inter alia, by including clinical communication education at all levels of the undergraduate curriculum. ${ }^{[1]}$

In 1983, Newble, quoted by Al-Kadri, ${ }^{[15]}$ observed that assessment drives learning. Since then, this point has been viewed as well proven, despite supportive evidence being fairly limited. Several researchers have aimed to explore the relationship between assessment and learning. Until recently, the effect of assessment on students' learning was unclear. ${ }^{[16]}$

In this study, assessment drives learning in that students are put under pressure to prepare for the OSCE. Benitez, ${ }^{[17]}$ however, believes that 
formative assessment - not summative assessment - drives learning. He makes the distinction that formative assessment is for learning and summative assessment is of learning, the latter being the more appropriate in making high-risk decisions. Assessment not only serves as motivation to learn skills and aid the facilitator in determining what students have learnt, but helps students to identify gaps in their learning. ${ }^{[18]}$ By applying assessment criteria, students self-assess what they know, or have done, and what they need to know or do next. ${ }^{[19]}$ Students who are learning to judge the quality of their work against well-defined criteria are developing invaluable skills for lifelong learning. ${ }^{[20]}$ Curriculum developers should be encouraged to consider the influence of assessments on what and how their students learn. ${ }^{[10]}$

Every experience evokes emotions, which is an important factor that affects thinking. ${ }^{[20]}$ Emotion may in some cases be facilitative, but it may also impede learning. ${ }^{[21]}$ As this was the participants' first experience of a simulated consultation, it seemed obvious that students' emotions were more likely to be anxiety and stress rather than a sense of enjoyment. Students can learn and perform better when feeling excited about the subject matter ${ }^{[22]}$ but anxiety may distract students' learning efforts by interfering with their ability to attend to tasks, as was reported by some participants. In some situations, emotions may influence the attentional processes, while in others they may directly influence the encoding and decoding of information. ${ }^{[2]}$ Students in this study experienced stress and the desire to cope with the situation. Epstein ${ }^{[23]}$ believes that once one has recognised negative emotions leading to maladaptive behaviours, one can implement strategies to gain control of those emotions. This corresponds to Sylwester's ${ }^{[24]}$ belief that students can learn how and when rational processes may be used to override their emotions, or to hold them in check. Sylwester also points out that activities that evoke emotions, such as simulations, may provide 'important contextual memory prompts' that will be helpful in recalling information during closely related events in the real world'.

\section{Conclusion}

Conducting an OSCE during which preclinical medical students were required to integrate their separately acquired procedural and communication skills in a simulated consultation, showed a deep divide between these two sets of skills. The poor performance in communication skills compared with procedural skills was repeated in the re-assessment. This may have been the detrimental effect of procedural and communication skills being taught and assessed separately and not in context. It is an indication that communication skills are neglected when teaching procedural skills and that the average student is not able to integrate these skills without practice. It appears that learning took place during this assessment and reflection event. Students learned from an authentic consultation: they integrated their procedural and communication skills and their knowledge and skills, they experienced the assessment as learning, and they became aware of the impact of emotion on their learning.

Acknowledgements. I would like to thank all the facilitators from the Skills Centre and the lecturers from the Practice of Medicine Division Centre, University of Limpopo (Medunsa Campus) who participated in the study. A special word of thanks to Dr Verona Sukrajh for help in identifying reflection themes and valuable comments with regard to the protocol and manuscript, and to Prof. Herman Schoeman, who did the statistical analyses.

\section{References}

1. Brown J. Clinical communication education in the United Kingdom: Some fresh insights. Acad Med 2012;87(8):1101-1104. [http://dx.doi.org/10.1097/ACM.0b013e31825ccbb4]

2. Kneebone R, Kidd J, Nestel D, Asvall A, Paraskeva P, Darzi A. An innovative model for teaching and learning clinical procedures. Med Educ 2002;36(7):628-634. [http://dx.doi.org/10.1046/j.1365-2923.2002.01261.x]

3. Kneebone R, Nestel D, Yadollahi F, et al. Assessing procedural skills in context: Exploring the feasibility of nneebone R, Nestel D, Yadollahi F, et al. Assessing procedural skills in context: Exploring the feasibility of
an Integrated Procedural Performance Instrument (IPPI). Med Educ 2006;40(11):1105-1114. [http://dx.doi. an Integrated Procedural Performance
org/10.1111/j.1365-2929.2006.02612.x]

4. Merriam-Webster Online Dictionary. Metacognition definition. 2012. http://www.merriam-webster.com/ 4. Merriam-Webster Online Dictionary. Metacogn
dictionary/metacognition (accessed 26 July 2013).

5. De Vos AS, Strydom H, Fouché CB, Delport CSL. Research at Grass Roots. Pretoria: Van Schaik, 2011.

6. UNT Health Centre for Learning and Development Assessment - measurement tools. http://www.hsc.unt.edu/ departments/cld/MeasurementsTools.cfm (accessed 17 May 2013).

7. Neal JM, Hsiung RL, Mulroy MF, et al. ASRA checklist improves trainee performance during a simulated episode of local anesthetic systemic toxicity. Region Anesth Pain Med 2012;37(1):8-15. [http://dx.doi.org/10.1097/ AAP.0b013e31823d825a]

8. Corbin J, Strauss A. Basics of Qualitative Research: Techniques and Procedures for Developing Grounded Theory3rd ed. Los Angeles, CA: Sage, 2008.

9. Herrington T, Herrington J, eds. Authentic Learning Environments in Higher Education. Hersley, PA Information Science Publishing 2006.

10. Nestel D, Kneebone R, Nolan C, Akhtar K, Darzi A. Formative assessment of procedural skills: Students' responses to the objective structured clinical examination and the integrated performance procedural instrument. Assessment he objective structured clinical examination and the integrated performance procedural instrument. As
and Evaluation in Higher Education 2011;36:171-183. [http://dx.doi.org/10.1080/02602930903221469]

11. Walker S, Armstrong KJ, Jarriel AJ. Standardized patients. Part 4: Training. International Journal of Athletic Therapy and Training 2011;18(2):20-23. http://www.academia.edu/1136199/Standardized_Patients_Part_4_
Theric Training (accessed 29 July 2013)

12. Kolb AY, Kolb DA. Learning styles and learning spaces: Enhancing experiential learning in higher education. Acad Manag Learn Educ 2005;4(2):193-212. [http://dx.doi.org/10.5465/AMLE.2005.17268566]

13. Rogers C. Defining reflection: Another look at John Dewey and reflective thinking. Teachers' College Records 2002;104(4):842-866.

14. Association of American Colleges and Universities (AACU), Carnegie Foundation for the Advancement of Teaching (CF). A statement on integrative learning. Integrative Learning: Opportunities to Connect, March 2004 5. Al-Kadri HMF. Does assessment drive students' learning? PhD. Maastricht University, the Netherlands. http:// arno.unimaas.n1/show.cgi?fid=25484 (accessed 7 August 2013).

16. Norman G, Neville A, Blake JM, Mueller B. Assessment steers learning down the right road: Impact of progress testing on licensing examination performance. Med Teach 2010;32(6):496-499. [http://dx.doi.org/10.3109/0142 159X.2010.486063]

17. Benitez J. Does assessment drive learning? Academic life in emergency. 2013. http://academiclifeinem.com/doesassessment-drive-learning/ (accessed 3 August 2013).

18. Prozesky D. Assessment of learning. Comm Eye Health 2001;14(38):27-28

19. Organisation for Economic Co-Operation and Development (OECD). Formative assessment: Improving learning in secondary classrooms. Policy brief. 2005. http://www.oecd.org/edu/ceri/35661078.pdf (accessed 23 July 2012). 20. Darling-Hammond L, Orcutt S, Strobel K, Kirsch E, Lit I, Martin D. Feelings count: Emotions and learning. The Learning Classroom 2013:89-95. http://www.learner.org/courses/learningclassroom/support/05_emotions learning.pdf (accessed 6 August 2013)

21. Pandey R. How do emotions aid in the learning process? Cognitive science and artificial thinking. 2012. http:// www.researchgate.net/post/What_emotions_do_in_learning_process (accessed 23 July 2012).

22. Oatley K, Nundy S. Rethinking the role of emotions in education. In: Olson D, Torrance N, eds. Handbook of Education and Human Development: New Models of Learning, Teaching and Schooling. Cambridge: Blackwell, 1996. 3. Epstein B. How emotions affect learning. Horizon Academy. http://www.horizon-academy.org/SiteResources/ Data/Templates/t2.asp?docid=659\&DocName=How\%20E (accessed 23 July 2013).

24. Sylwester R. How emotions affect learning. Educ Leadership 1994;52(2):60-65. http://www.ascd.org/ publications/educational-leadership/oct94/vol52/num02/How-Emotions-Affect-Learning.aspx (accessed 3 August 2012). 